\title{
Régulation de la morphogenèse neuronale par l'homéodomaine des gènes antennapedia
}

Nous avons décrit les premiers éléments d'une stratégie permettant d'analyser le rôle des protéines à homéoboîte dans la formation des circuits neuronaux, ainsi que les mécanismes mis en œuvre dans ce processus.

L'idée de départ était de s'opposer à l'action des protéines à homéoboîte (homeobox) existant éventuellement dans les cellules en bloquant les sites de fixation présents dans les promoteurs des gènes cibles. Pour ce, nous avons synthétisé le peptide homéoboîte (60 acides aminés) de la protéine Antennapedia* et nous l'avons fait pénétrer dans les cellules nerveuses par une technique très simple de trituration des neurones mise au point par Borasio et ses collaborateurs (Munich, Allemagne).

Nous avons vérifié que le peptide seul se fixe bien aux promoteurs ayant la séquence consensus de reconnaissance par les homéoboîtes et qu'il se localise dans le noyau après pénétration dans les cellules. Le résultat de cette opération est une intense différenciation morphologique des neurones en culture [1]. Par ailleurs, nous avons constaté que le peptide ajouté aux cellules déjà mises en culture depuis 24 heures pénètre de lui-même et atteint le noyau. Le résultat étant, de nouveau, une forte différenciation morphologique des cellules.

Les conclusions de ce travail sont multiples. (1) L'inhibition de la fixation des protéines à homéoboîte sur leurs promoteurs pourrait conduire à une forte stimulation de la croissance neuritique. Le conditionnel est utilisé

\footnotetext{
* Antennapedia : gène homéotique de la drosophile.
}

ici pour indiquer que, bien que le peptide soit doué de la capacité spécifique de fixation et qu'il pénètre dans le noyau, nous n'avons pas formellement établi de relation causale entre ces deux propriétés et la différenciation morphologique observée. La production en cours de différents peptides mutés devrait permettre de répondre à cette question. (2) Il existe un système de capture du peptide. Dans un travail en cours de rédaction nous démontrons que ce système est spécifique des cellules nerveuses et implique la fixation du peptide sur un sucre: l'acide polysialique $\alpha$ 2-8 porté uniquement par la molécule d'adhérence neuronale N-CAM

Les implications et spéculations sont également multiples. (1) Sur le plan technique, l'identification d'un système simple de transport transmembranaire permettant de faire pénétrer un peptide de $7 \mathrm{kDa}$ et de l'adresser au noyau ouvre une voie d'approche nouvelle à la pharmacologie cellulaire. Il s'agira de rechercher si ce même peptide lié à d'autres composants peptidiques ou nucléotidiques peut également pénétrer. (2) Sur le plan fondamental, il faudra comprendre s'il s'agit là d'un artefact, certes utile mais limité dans sa signification biologique, ou bien si nous nous trouvons devant la mise en évidence d'une propriété restée inaperçue de certaines protéines capables de se lier à l'ADN, d'agir non seulement de façon intracrine, mais également autocrine ou paracrine.

A. P.

1. Joliot A, Pernelle C, De Agostini-Bazin H, Prochiantz A. Antennapedia homeobox peptide regulates neural morphogenesis. Proc Nall Acad Sci USA 1991; 88 : 1864-8.
Un nouvel antibiotique actif contre la lèpre. Depuis 1940, la lèpre, clue à une infection par Mycobacterium leprae, est efficacement traitée par les sulfones (dlapsone). Ce médicament est cependant peu actif si bien que le traitement doit durer des années. De plus, des résistances importantes sont apparues au milieu des années 1970. Heureusement, d'autres antibiotiques ont alors été ajoutés à l'arsenal thérapeutique antilìpre: la rifampicine et la clofazimine. A l'heure actuelle, une triple chimiothérapie est proposéc. Le produit le plus actif est la rifampicine, qui peut guérir les malades en six mois. Lorsque les souches de M. Léprae sont résistantes à cet antibiotique, le traitement par la clofazimine et la dapsone doit durer de deux à trois ans. Un nouvel antibiotique, l'olloxacine, s'avère être pratiquement aussi eflicace que la rifampicine [1]. Des te'sts sur le terrain vont maintenant débuter, appréciant l'eflicacité d'une triple chimiothérapie par la rifampicine, l'ofloxacine et la dapsone. Il existe certains espoirs que l'association rifampicine/olloxacine puisse permettre de réduire à quelques mois la durée nécessaire du traitement pour parvenir à la guérison. Cette nouvelle chimiothérapic est particulièrement la bienvenue car le développement de l'épidémic de SIDA en Afrique créc une nouvelle menace de recrudescence de la lèpre celle-ci ne frappe en effet que le dixième des individus en contact avec des lépreux, les autres étant supposés protégés par leur système immunitaire. Parmi les sujets infectés, ceux ayant un système immunitaire non déprimé développent une forme pauci-bacillaire alors que les sujets immuno-déprimés développent une forme beaucoup plus grave, multibacillaire. L'immunodépression crééc par le virus du SIDA pourrait bien augmenter la contagiosité de la lèpre, ainsi que la proportion des formes graves.

11. Sattaur O. New Scientist 1991 129: 20.] 